in such cases a means should be available for fixing the shoes to the footplate without running the risk of producing damage to the soft tissues. A metal rim shaped to the sole of the shoe together with a retaining band or strap across the instep is far preferable to the combination of instep strap and calf strap so commonly used. Such a rim can be bolted to the foot plates and need take up very little more room than the occupant's shoes.

Despite the marked improvement in chair designs in the last few yearsindeed in some cases perhaps because of improvements-the overall weight of the average general purpose chair has not been reduced as much as the average user would like. Thanks to improved methods of rehabilitation, the majority of paraplegics today in this country can lead very useful lives in the community. Many of them, especially the ladies, find it difficult to lift the chair into a car or motor tricycle. I understand that wheelchairs made of light metal alloy weighing only about $20 \mathrm{lb}$. have been produced and proved to be stable and durable. Such a chair would be a tremendous boon to paraplegics and I hope it will be made available to them in this country in the very near future.

Finally, I would like to suggest that everyone concerned with the supply of wheelchairs to the disabled, from the doctor who first recommends the chair to the British Railway employee who finally delivers it, should make a concerted effort to reduce the period, often of several weeks, at present commonly required to effect delivery.

\title{
THE SPASTIC AND HIS WHEELCHAIR
}

\author{
By Ronald MacKeith, M.A., D.M., F.R.C.P. \\ Consultant Paediatrician, Guy's Hospital, London
}

THE spastic has usually more than his motor handicap to contend with for cerebral palsy is itself a 'symposium of handicaps, sensory, motor, intellectual, emotional and social'. But by prolonged training of his capacities as well as for his handicaps, the spastic is being helped to a useful place that only a few years ago was denied to him. To this change the Spastic Society has contributed a great deal.

\section{THE STATIONARY CHAIR}

In the care and treatment of the spastic the stationary chair frequently plays an important part. The stationary chair is used to increase the child's experience by putting him in a position in which he can see the world and use his upper limbs; it is used to assist the treatment of the child both by correcting and by facilitating movements; it is used to support the trunk and to provide security for the child. The difference in what is needed for a wheelchair for the spastic and the difference of his needs from those of the paraplegic and the amputee can probably be best initially approached by closer study of what we want of the stationary chair for spastics and then moving on to consideration of the spastic's wheelchair.

Furthermore, both stationary chair and wheelchair have in common certain basic requirements. If we achieve simplicity, lightness, good design, stability, cleanliness, comfort and, of great importance, a good fit for the stationary chair it will be the easier to achieve these in wheelchairs. 


\section{THE PURPOSE OF THE WHEELCHAIR}

The purpose of a wheelchair is to give greater mobility. This includes passive mobility and active mobility. By passive mobility I mean the mobility we give an infant by putting him in a perambulator. This is largely for the convenience of the infant's attendants, but for him it may mean that it becomes possible for him to be taken, for example, to the welfare clinic. The spastic's mobility may be limited because he cannot walk, because he cannot walk far, or because he js slow at getting about. Without the use of an attendant-propelled chair, the organisation of the spastic's life at school, whether day school or boarding, with the movement from classroom to dining-room to treatment room, would scarcely be possible.

But the aim is, wherever possible, that the chair shall not be attendant-propelled but self-propelled, for this gives the spastic not only mobility but independent mobility.

Even so, with the younger child the doctor weighs whether the delights of swift self-propelled movement in a chair will discourage the child from his arduous efforts to learn to get about on his own legs. With the older patient and especially at adolescence, the doctor often has a different problem. He may have to decide whether to abandon efforts to teach a slow awkward walking and to settle for giving competence in a wheelchair life. We know how the parents of the young child are always concerned about when the child will walk at a time when the doctor is more concerned that the child should learn to talk and to sit. Sometimes the doctor puts an unwise pressure on an adolescent to walk when the patient will never be able to move more than very slowly and a very short distance. The decision to settle for a a wheelchair life is a difficult one, but one which has to be met.

The decision will be affected by the wishes of the patient and by the reactions his method of getting about may produce in those he meets. In recent experiments normal people and spastics were shown photographs of various people with handicaps and asked to say which they felt most repugnance to. The handicaps shown were a leg brace, a wheelchair, a slight facial disfigurement and obesity. There was least negative reaction to the person with the leg brace and the most acceptable was in the wheelchair. A recent issue of Spastics News carried a vivid description of the difficulties of travelling with an athetoid adult, but it was the grimacing that repelled, not the wheelchair.

\section{DEFECTS OF EXISTENT WHEELCHAIRS}

The existent wheelchairs for spastics are criticised as:

Too heavy.

Difficult to manœuvre.

There is a lack of range of sizes, especially for smaller children.

The chairs are often too wide.

The slung seats and back are uncomfortable.

The footrests are difficult to pull up and down.

The brakes are inadequate or tend to become so.

There is lack of protection for hands and clothing from the driving wheels.

There are in addition, criticisms which are more particularly true when the use of wheelchairs for spastics are considered: 
Gripping the wheels is difficult, so that an alternative propelling system, perhaps by levers, is desirable.

There is difficulty in restraining involuntary movements of limbs sometimes.

Patients may tend to slide out of the chair from extensor thrust.

The problem of head support often presents difficulties. Sometimes there is head extension. More commonly the unsolved problem is of the patient with weak neck muscles.

There is difficulty in obtaining chairs with head and limb retaining devices through National Health Service channels.

\title{
THE DESIDERATA FOR THE SPASTIC'S WHEELCHAIR
}

The chair the spastic wants must have these properties:

Chairs should be available without delay, for spastics may be immobilised while waiting for them, and children may have grown out of the size ordered.

Stability. It must not tip when the patient moves about in the chair, nor when he is getting in or out of it.

Accessibility. He must be able to get in and out of it easily.

A Good Fit. To achieve a good fit, a good system of measuring and the possibility of trying various chairs are both necessary. The change in size of children as they grow will need frequent change or modification of his chair.

Comfort. This depends on the correct angle of the back, which should be variable, for sometimes the occupant will want to relax and sometimes to sit up more; on the length of the backrest; on suitable padding, not soft, not wooden hard, for the patient may sit in the chair for hours; on adequate support for the patient's thighs.

\section{ERGONOMIC PRINCIPLES IN THE USE OF WHEELCHAIRS}

\author{
By W. Floyd, B.Sc., Ph.D., F.Inst.P., A.M.I.E.E. \\ Head of the Department of Ergonomics, Loughborough College of Technology
}

ERGONOMICS deals with the capabilities and limitations of human performance in all its aspects, including the effects of age and disabilities on skill, work output, endurance and other facets of human performance.

Ergonomics also concerns itself with the proper use of human abilities and the best ways in which to use them; for example, in controlling machines so as to obtain a required degree of precision or quality of output. This involves the study of human faculties as part of a Man-Machine system. Such a study includes, for instance, the questions of the input and the output of the system looked at from the points of view of accuracy, speed, energy, fatigue and the like.

The object of such a study is to answer two questions: What action can and should be carried on by the machine? and What action can and should be done by the man? This approach demands collaboration between the human biologist, 